\title{
BIOLOGICAL REPAIR OF INDIRECT INGUINAL HERNIA USING THE HERNIAL SAC
}

\author{
Debabrata Singha1 ${ }^{1}$, Nitesh Kumar², Naresh Pawar³, Khorshid Alam Hussain ${ }^{4}$, Manoj Kumar Singh ${ }^{5}$
}

${ }^{1}$ Associate Professor, Department of General Surgery, Silchar Medical College.

2 Postgraduate Trainee, Department of General Surgery, Silchar Medical College.

${ }^{3}$ Postgraduate Trainee, Department of General Surgery, Silchar Medical College.

4 Postgraduate Trainee, Department of General Surgery, Silchar Medical College.

5 Postgraduate Trainee, Department of General Surgery, Silchar Medical College.

\section{ABSTRACT}

\section{BACKGROUND}

Inguinal hernia is a common surgical problem. The current era of repair with use of mesh is associated with many chronic problems and its cost and availability is also a concern in developing countries. There is a need for developing autologous tissue repairs. The hernial sac is used in a novel way in our study for the repair of the hernia.

\section{MATERIALS AND METHODS}

A prospective study of utilising the hernial sac in repair of indirect inguinal hernia was carried out in Silchar Medical College and Hospital for a period of 2 years with minimum 1 year followup. Hernial sac was dissected out in the region of deep ring and a vessel sparing ligation was done without herniotomy. Hernial sac distal to superficial ring was discarded and left open. Sac was folded and incorporated between the inguinal ligament and the internal oblique or conjoined tendon with polypropylene in a tensionless manner to create a new reinforced posterior wall. Cord was laid subaponeurotic. Cases were followed up for complications and recurrence.

\section{RESULTS}

Fifty male patients were operated. The mean age was $41.6 \pm 13.34$. Mean operating time was 72.56 minutes, almost comparable with the Lichtenstein repair. Post-operative pain on VAS scale was averaging 3.7. Very few (16\%) patients required regular analgesics after discharge. Two patients developed seroma. Average hospital stay was 2.3 days. Only one (2\%) patient developed recurrence.

\section{CONCLUSION}

Sac of indirect inguinal hernia can be used with promising results in repair of indirect inguinal hernias.

\section{KEYWORDS}

Inguinal Hernia, Hernial Sac, Biological Repair, Non-Mesh Repair.

HOW TO CITE THIS ARTICLE: Singha D, Kumar N, Pawar N, et al. Biological repair of indirect inguinal hernia using the hernial SAC. J. Evolution Med. Dent. Sci. 2017;6(17):1357-1361, DOI: 10.14260/Jemds/2017/295

\begin{abstract}
BACKGROUND
Inguinal hernia is a common surgical problem and many surgical techniques of repair have come, still there is no gold standard operative technique.[1] Lichtenstein tension free repair is the most popular technique in current scenario and is being recommended by the European Hernia Society (EHS).[2] But it also has some disadvantages like the cost and availability of mesh.[3] And has complications like foreign body sensation in groin, discomfort and abdominal wall stiffness, mesh migration, chronic groin sepsis, meshoma, affected sexual functions and inguinodynia. ${ }^{[3-8,1]}$

These complications have influenced for the search of new techniques of hernia repair amongst the surgeons. Biological repairs after the era of mesh repair have been placed behind the curtains. Only Shouldice repair is a

well-known biological repair till date. Desarda presented a pure tissue repair with use of external oblique aponeurosis which eliminated the complications related to mesh and was more physiological.[9] Fischer emphasises on the need for biological repairs.[10]

Alcino Lazaro in 1971 studied the hernial sac in regards of its constitution and its utilisation in reinforcing the hernial defects with good results. Halsted said about the finding of radical cure of hernia repair if a tissue with same characteristics of fascia or tendon is found for repair.[11-12] Artur Laizo identified smooth muscle fibres in histology of hernial sac which were independent of the blood vessels in his study.[13] In this study, the hernial sac has been utilised for repair of the posterior wall of the inguinal canal in a more physiological and biocompatible way.
\end{abstract}

Financial or Other, Competing Interest: None.

Submission 26-12-2016, Peer Review 14-02-2017,

Acceptance 20-02-2017, Published 27-02-2017.

Corresponding Author:

Dr. Nitesh Kumar,

Room No. 12, Old PG Hostel,

Silchar Medical College and Hospital

Silchar, Cachar

Assam-788014

E-mail: niteshkal@gmail.com

DOI: $10.14260 /$ jemds $/ 2017 / 295$

(c) $($ ) $\$$

\section{MATERIALS AND METHODS}

A prospective study was carried out in Silchar Medical College and Hospital, Assam, India during July 2013 to June 2015. Patients presenting with indirect inguinal hernia above the age of 18 years were included in the study. Very small indirect, hernias with very thin sac and direct hernias were excluded. Preoperative investigations were done to ensure the fitness of the patient for spinal anaesthesia. Any factor responsible for precipitating or exaggerating patient's hernia was thoroughly sought for and treated. 
Spinal anaesthesia was given to fit patients and local anaesthesia was used in others. Pre-operative dose of IV antibiotic was given. Skin incision was made $2 \mathrm{~cm}$ above and parallel to medial half of inguinal ligament. External oblique aponeurosis was divided along the direction of its fibres and the superficial ring was opened. Superior and inferior flaps were raised to expose the internal oblique or conjoined tendon and the inguinal ligament respectively. Spermatic cord was isolated, cremasteric fascia was opened and sac was identified.

Point of sac corresponding to the pubic tubercle was marked and sac was dissected circumferentially from the cord structures at that place. Sac was opened and inspected for thickness. Patients with too thin sacs were not included in the study. Distal sac was dissected and discarded. Proximal sac was circumferentially dissected again at the region of the deep inguinal ring retaining some of the attachment of the sac with cord structures in the middle part for vascularity (Fig. 1, 3). Ligation of the sac was done at the deep inguinal ring with sparing of one or two prominent vessels of the sac in a purse string manner. The inside of the sac was inspected to exclude any content and confirmation of the complete closure of the lumen of sac (Fig. 2). Ligated sac was not divided and its attachment was maintained in situ. Sac was opened distally (Fig. 3, 4).

Posterior wall of the inguinal canal was inspected. The sac was incorporated between the conjoint tendon and the inguinal ligament with the help of interrupted 1-0 Prolene. The most distal bite was taken with the anterior rectus sheath, just before its insertion into pubis. Conjoint tendon was fixed loosely with the inguinal ligament with three or four sutures incorporating and folding the sac upon itself between these two structures (Fig. 5, 6). The suture close to the deep inguinal ring took care of the size of the deep ring. Few additional sutures were placed to fix the sac with the conjoint tendon superiorly and the inguinal ligament inferiorly with Prolene, either interrupted or continuous (Fig. $6,7)$. This resulted in the sac placed behind the cord to form new posterior wall of the inguinal canal. Patient was asked to cough after the repair and the strength of the posterior wall was assessed by its movements. Cord remained subaponeurotic. External oblique aponeurosis was closed with 2-0 Prolene and skin was closed with 2-0 nylon.

In postoperative period, pain was assessed using the Visual Analogue Pain Scale 0 (minimum) and 10 (maximum). Pain was also recorded with Sheffield scale: 0 , no pain; 1 , no pain at rest but it appears during movement; 2 , temporary pain at rest and moderate during movement; 3 , constant pain at rest and severe during movements. Patients were continued on IV antibiotics for next 24 hours. Uncomplicated cases were discharged on day 2. Patients were followed on day 7, 28, 6 months, 12 months and 24 months. Data were collected in followup period for wound infection, seroma, haematoma, postoperative hospital stay, return to normal activity, and recurrence. Data was analysed with SPSS software and appropriate statistics were used.

\section{RESULTS}

Fifty patients were operated using this technique in our hospital. All were males. Right-sided hernias were 36 and left sided were 14. Most patients were in age group 41 to 55 and the mean age was $41.6 \pm 13.34$ (Table 1 ). Mean operating time was 72.56 minutes, almost comparable with the Lichtenstein repair. Post-operative pain on VAS scale was averaging 3.7 (Table 2). Very few (16\%) patients required regular analgesics after discharge. None of the patients developed wound infection. Seroma formed in two (4\%) patients and was drained by removing one of the stitches. None of the patients developed haematoma. Average hospital stay was 2.3 days. Return to normal household activities was 4.8 days (average). Only one (2\%) patient developed recurrence. None of the patients complained of inguinal pain after 6 months or any foreign body sensation.

\begin{tabular}{|c|c|}
\hline Age & No. of Patients \\
\hline $18-25$ & 08 \\
\hline $26-40$ & 14 \\
\hline $41-55$ & 22 \\
\hline $56-70$ & 05 \\
\hline$>70$ & 01 \\
\hline \multicolumn{2}{|c|}{ Table 1. Age Distribution } \\
\hline
\end{tabular}

\begin{tabular}{|l|c|}
\hline \multicolumn{1}{|c|}{ Sheffield Pain Scale } & $\begin{array}{c}\text { No. of } \\
\text { Patients }\end{array}$ \\
\hline 0- No pain & 06 \\
\hline 1- No pain at rest but appears at movement & 26 \\
\hline $\begin{array}{c}\text { 2- Temporary pain at rest and } \\
\text { moderate during movements }\end{array}$ & 16 \\
\hline $\begin{array}{c}\text { 3- Constant pain at rest and severe } \\
\text { during movements }\end{array}$ & 02 \\
\hline Table 2. Sheffield Pain Score taken on day 1 Morning \\
Rounds
\end{tabular}

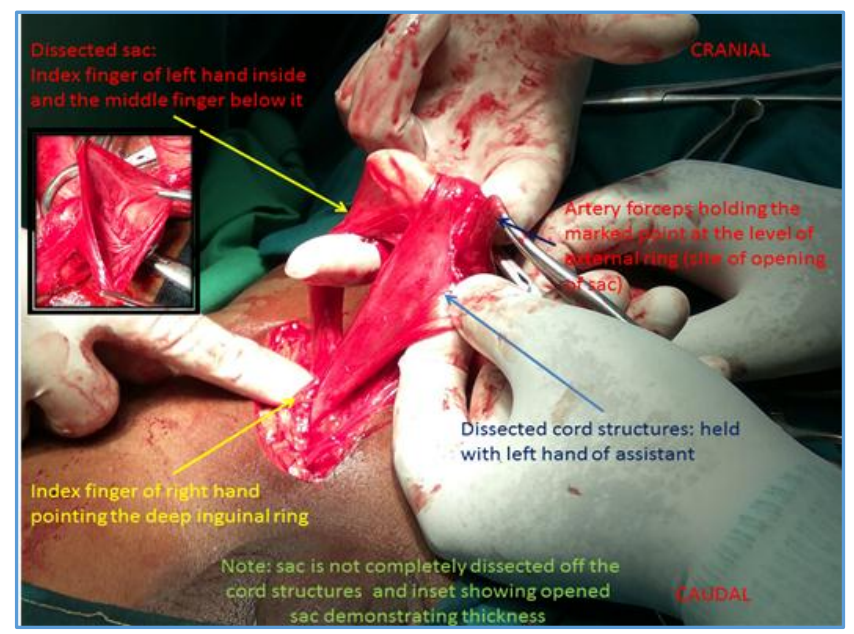

Figure 1. Dissected Sac and Cord structures and the thickness of Sac being Displayed 


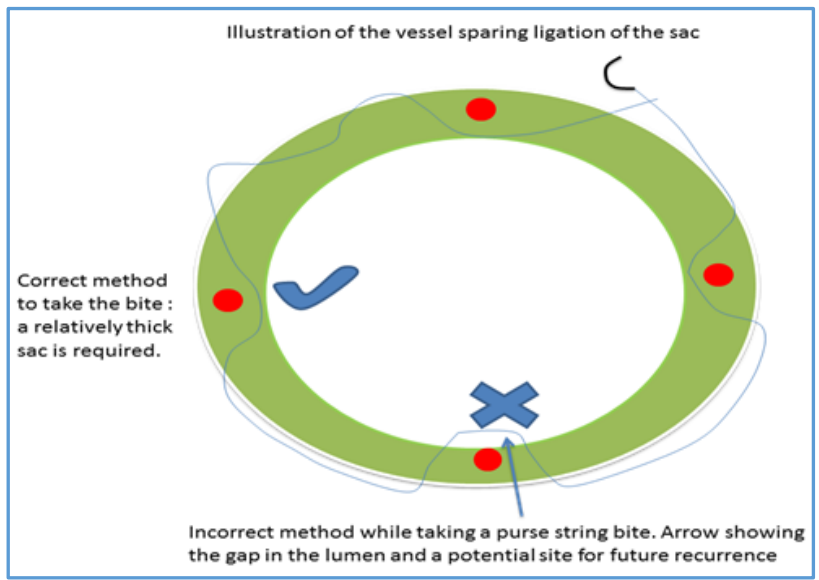

Figure 2. Diagrammatic representation of the Vessel Sparing Ligation of the Sac

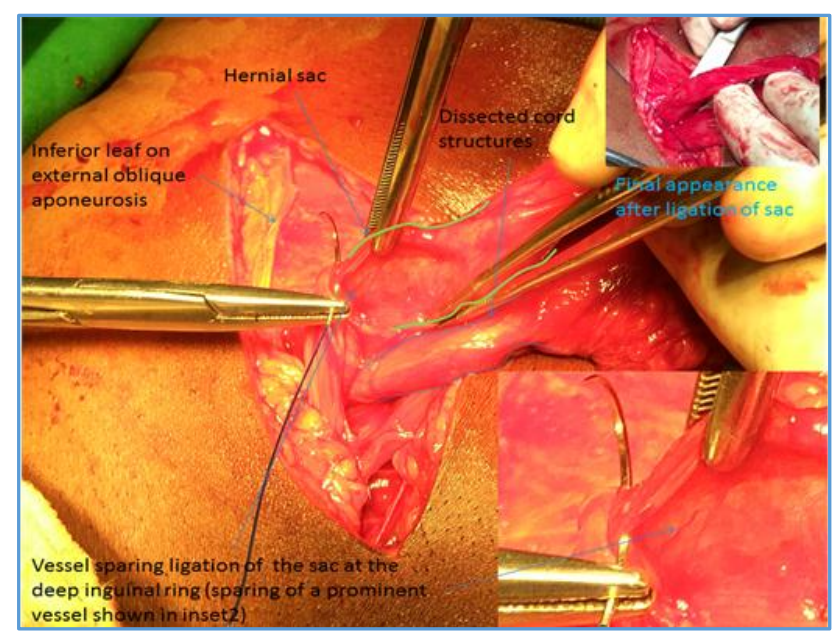

Figure 3. Vessel sparing Ligation of the Sac at the Deep Ring

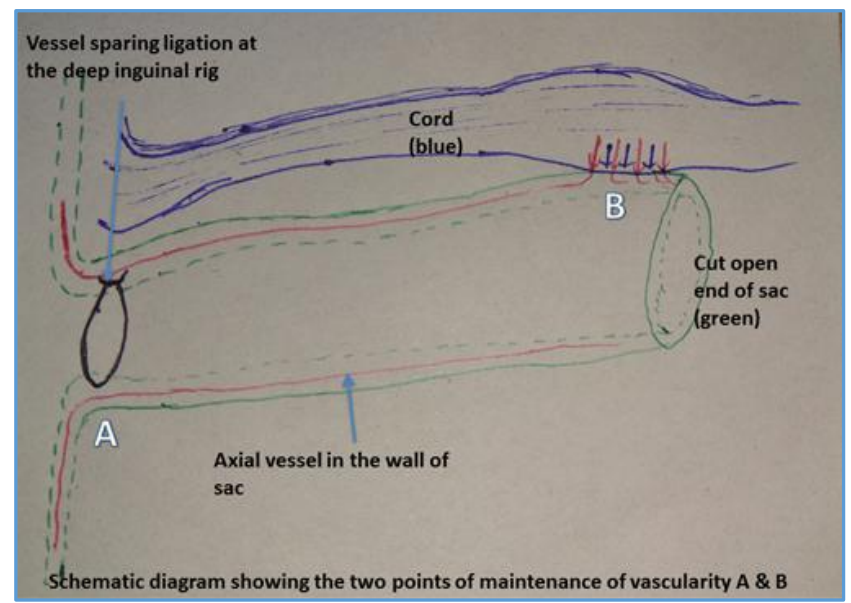

Figure 4. Schematic Diagram showing the Maintenance of Vascularity of the Sac

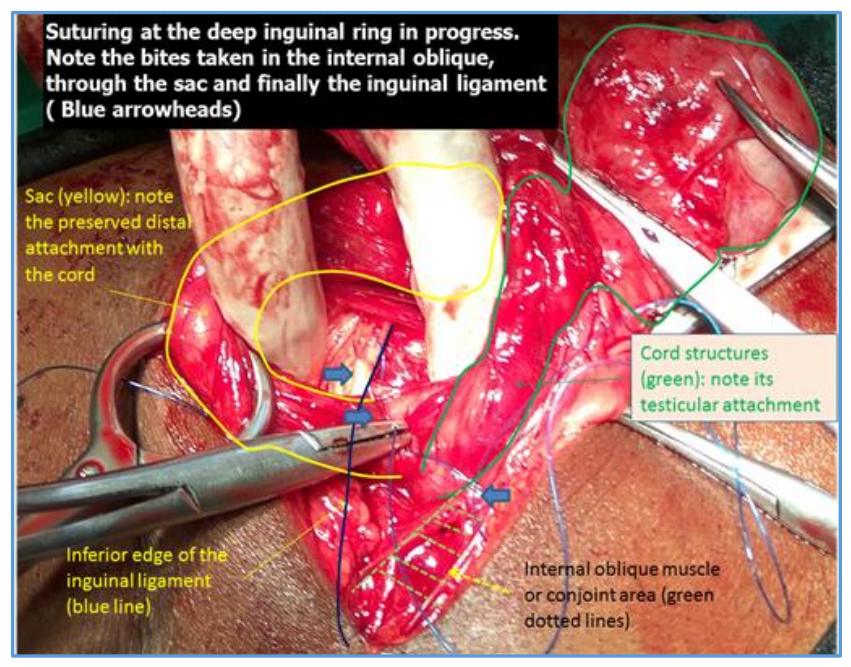

Figure 5. Incorporating the Sac between the Internal Oblique/Conjoined tendon and the Inguinal Ligament, forming the new Reinforced Posterior Wall

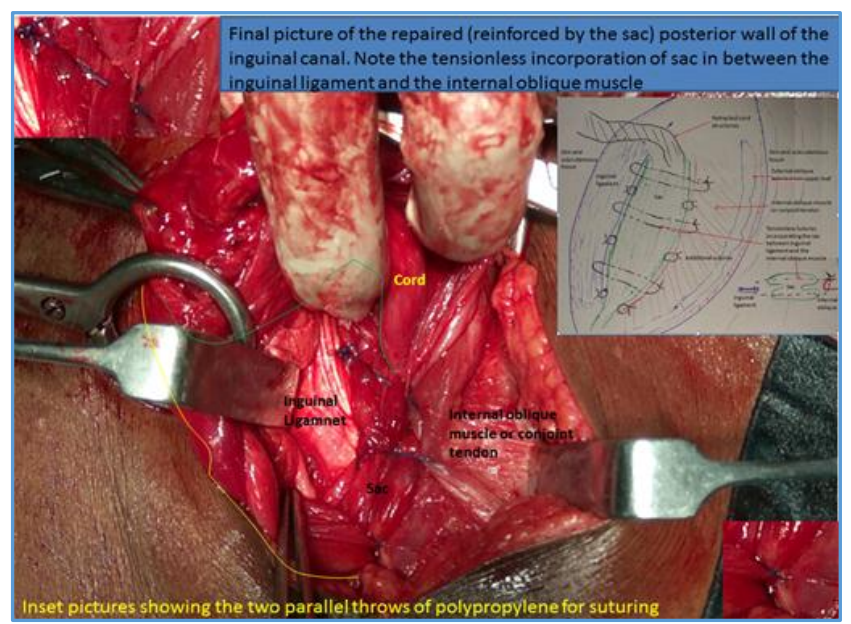

Figure 6. Repaired and Reinforced Posterior Wall inset Picture showing the Schematic Diagram

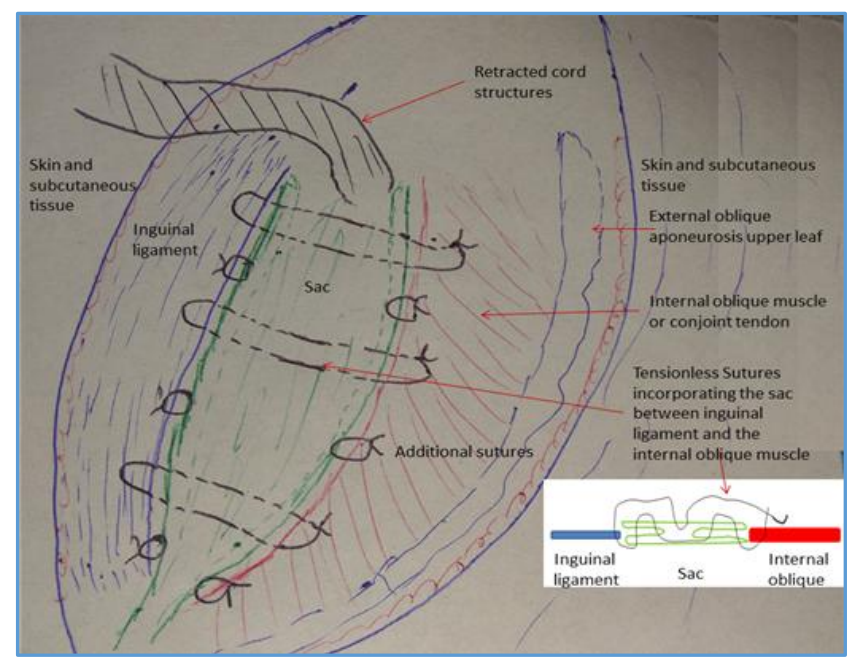

Figure 7. Schematic Diagram of the Technique of Utilising the Sac in the Tensionless Repair of Posterior Wall 


\section{DISCUSSION}

Tissue based physiological repairs are required in current scenario to overcome the complications related with prosthetic meshes. Lichtenstein tension free repair is the most popular technique but is related to complications, all related to use of mesh. Foreign body sensation in groin, discomfort and abdominal wall stiffness mesh migration, chronic groin sepsis, meshoma, affected sexual functions and inguinodynia are the mesh related complications. ${ }^{[3-8,14]}$ Major worsening of quality of life is also found in some cases. Efforts to improve results of hernia treatment are going on and major results are seen in improving the quality of mesh. Lightweight polypropylene meshes, composite meshes and many biological prosthesis are being tested. But very less importance is given for search of a new tissue based biological repairs..$^{[3,4,10]}$

Shouldice technique is a well-known tissue repair but has steep learning curve and is related to more complications while operating on the fascia transversalis.[15] It does not follow the principle of tension free repairs and has more recurrences in poorly trained hands.[15] Alcino Lazaro in 1971 used the hernial sac for the first time for correction of abdominal hernia. Later A. Laizo reported use of hernial sac as a mesh in his study of 200 patients. But he did a Bassini repair first and then applied the excised sac in a similar manner as a mesh.[11] His repair was not tension free and the chances of survival of the devascularised sac could not be assessed.

Desarda used an undetached strip of external oblique aponeurosis for the repair of the posterior inguinal wall [9]. Later he described the surgical pathology of inguinal hernia repair.[16] He emphasised on providing a strong and physiologically dynamic posterior wall. Posterior wall became weak when the aponeurotic extensions of the transverses abdominis muscle were absent. Therefore, any new approach to inguinal hernia repair must consider replacing this element with any other suitable structure or material. He also demonstrated improved contractions of the muscle arch after it received a new anchorage.[16]

In our study, a relatively thick sac folded upon itself was used for the repair of the weakened posterior wall. Few prominent vessels in the hernial sac were identified and a vessel sparing ligation of the sac was done at the deep ring. The hernial sac was not cut at the deep ring and its attachment was also maintained at some places distally with the cord structures for a viable blood supply. The repair was tension free as the sac was incorporated between the free edges of the conjoint muscles and the inguinal ligament. In direct hernias and small indirect hernias, the small sac could not be utilised for repair. Repair was more physiological as it provided new anchorage to the internal oblique muscles and focused on the reinforcement of the weakened posterior wall which is mainly responsible for hernia formation. Thus, the connective tissue of the posterior wall was reinforced by a sac having characteristics of fascia and some muscle fibers.[13] The post-operative pain was comparable with other studies.[3,15] There was no chronic inguinal pain, no foreign body sensation and no feeling of stiff abdominal wall after 6 months. There was only $2 \%$ recurrence in our study.

\section{CONCLUSION}

Hernial sac is a tough tissue having characteristics of a fascia. It can be utilised in repair of the indirect inguinal hernias and it acts as a more physiological and a dynamic posterior wall. The repair is more biocompatible and tension free. The complications of mesh can be avoided with a negligible recurrence rate. At present the number of cases is small, but the study is ongoing to include more cases and a longer followup.

\section{REFERENCES}

[1] Rutkow IM. Demographic and socioeconomic aspects of hernia repair in the United States in 2003. Surgical Clinics of North America 2003;83(5):1045-51.

[2] Simons MP, Aufenacker T, Bay-Nielsen M, et al. European hernia society guidelines on the treatment of inguinal hernia in adult patients. Hernia 2009;13(4):343-403.

[3] Situma SM, Kaggwa S, Masiira NM, et al. Comparison of Desarda versus modified Bassini inguinal hernia repair: a randomized controlled trial. East Cent Afr J Surg 2009;14(2):70-6.

[4] Szopinski J, Dabrowiecki S, Pierscinski S, et al. Desarda versus Lichtenstein technique for primary inguinal hernia treatment: 3-year results of a randomized clinical trial. World J Surg 2012;36(5):984-92.

[5] D'Amore L, Gossetti F, Vermeil V, et al. Long-term discomfort after plug and patch hernioplasty. Hernia 2008;12(4):445-6.

[6] Scott NW, McCormack K, Graham P, et al. Open mesh versus non-mesh for repair of femoral and inguinal hernia. Cochrane Database Syst Rev 2001;2:CD002197.

[7] Miller JP, Acar F, Kaimaktchiev VB, et al. Pathology of ilioinguinal neuropathy produced by mesh entrapment: case report and literature review. Hernia 2008;12(2):213-6.

[8] Robinson TN, Clarke JH, Schoen J, et al. Major meshrelated complications following hernia repair: events reported to the food and drug administration. Surg Endosc 2005;19(12):1556-60.

[9] Desarda MP. Inguinal herniorrhaphy with an undetached strip of external oblique aponeurosis: a new approach used in 400 patients. The European Journal of Surgery 2001;167(6):443-8.

[10] Fischer JE. Surgery of hernia. In: Fischer's master of surgery. $6^{\text {th }}$ edn. Philadelphia: Wolters Kluwer Health/Lippincott Williams \& Wilkins 2012:2061-2.

[11] Laizo A, da Fonseca Delgado FE, Terzella MR, et al. Repair of the inguinal hernia using the hernia sac to correct the abdominal wall defect. G Chir 2013;34(78):195-7.

[12] Barbosa, CA, Fonseca do Amaral V, Lázaro da Silva A. Histopathology of the hernial sac in indirect inguinal hernia and in the parietal peritoneum in adults and children: a qualitative study of its smooth muscle. Revista do Colégio Brasileiro de Cirurgiões 2000;27(3):183-8. 
[13] Laizo A, Vasconcelos RS, Gollner AM, et al. Hernial sac histology of the inguinal hernias: identification of smooth muscle fibers and their relation with the blood vessel. Rev Col Bras Cir 2009;36(4):323-6.

[14] Desarda MP. Surgical physiology of inguinal hernia repair-a study of 200 cases. BMC surgery 2003;3(2):1.
[15] Nordin P, Bartelmess P, Jansson C, et al. Randomized trial of Lichtenstein versus Shouldice hernia repair in general surgical practice. Br J Surg 2002;89(1):45-9.

[16] Hakeem A, Shanmugam V. Inguinodynia following Lichtenstein tension-free hernia repair: a review. World J Gastroenterol 2011;17(14):1791-6. 